\title{
Um Caso Atípico de Polimiosite com Acometimento da Língua(*)
}

\section{An Atypical Case of Polymyositis with Tongue Involvement}

\author{
Acir Rachid $^{(1)}$, Francisco Luiz G. M. Magalhães ${ }^{(2)}$, Carlos Frederico R. Parchen ${ }^{(3)}$, \\ Vanise Campos G. Amaral ${ }^{(4)}$, Orlando Lopata ${ }^{(5)}$
}

\section{RESUMO}

A polimiosite (PM) é uma enfermidade sistêmica idiopática caracterizada por um processo inflamatório não supurativo que acomete a musculatura esquelética e manifesta-se clinicamente por fraqueza muscular proximal e simétrica. Relatamos um caso interessante e incomum de PM cuja manifestação inicial foi o envolvimento da língua de uma mulher de 54 anos com glossodínia e extensa investigação prévia inconclusiva. Na revisão da literatura realizada encontramos somente uma descrição análoga; portanto, achamos relevante esta publicação, que constitui provavelmente o segundo caso descrito na literatura internacional.

Palavras-chave: polimiosite, glossodínia, miopatia, dermatomiosite.

\section{INTRODUÇÃO}

A polimiosite (PM) é uma doença sistêmica do tecido conjuntivo, cujo achado clínico predominante é a fraqueza muscular proximal e simétrica. Possui incidência variável geograficamente, com cerca de um caso para cada 100 mil habitantes, havendo predominância no sexo feminino. Sua fisiopatologia é desconhecida, e dentre os mecanismos mais prováveis sugere-se injúria muscular mediada por vírus ou insulto microvascular por auto-antígenos musculares ${ }^{(1-3)}$.

A fraqueza muscular é o principal sintoma que induz a suspeita diagnóstica, sendo simétrica, bilateral e proximal, acometendo músculos da cintura escapular e pélvica e progredindo para a musculatura proximal dos membros ${ }^{(4)}$.

\begin{abstract}
Polymyositis is an idiopathic systemic disease, characterized by an inflammatory non-supurative process in the skeletal muscle tissue, whose main clinical feature is symmetrical proximal muscle weakness.

We report an uncommon and interesting case of polymyositis whose dominant manifestation was tongue involvement in a 54 year-old woman with glossodynia and previous extensive, inconclusive investigation. In the literature, we found only one similar case published; therefore, this could be the second case described in the international literature.
\end{abstract}

Keywords: polymyositis, glossodynia, myopathy, dermatomyositis.

O início é freqüentemente gradual e progressivo. O comprometimento da musculatura esquelética da parede posterior da faringe e do terço proximal do esôfago pode dar origem à disfagia alta, com refluxo de alimentos para vias aéreas altas e disfonia. O comprometimento do flexor do pescoço ocorre em dois terços dos casos, o que pode ocasionar dificuldade para sustentar o pescoço. Os sintomas constitucionais incluem fadiga, febre baixa, perda de peso, artralgia ou artrite de pequenas e médias articulações ${ }^{(5)}$.

O envolvimento cardíaco geralmente se traduz por taquicardia, arritmias, defeitos da condução átrio-ventricular e bloqueios de ramos. Raramente há insuficiência cardíaca congestiva, seja por miocardite, seja por fibrose miocárdica ${ }^{(6)}$.

\footnotetext{
* Trabalho realizado no Departamento de Clínica Médica do Hospital de Clínicas da Universidade Federal do Paraná (UFPR), Curitiba, PR, Brasil. Recebido em 9/10/2003. Aprovado, após revisão, em 11/4/2005

1. Professor Emérito da UFPR. Professor Sênior do Departamento de Clínica Médica da UFPR. Livre-docente em Reumatologia e Professor Titular da Disciplina de Clínica Médica da UFPR. Chefe do Setor IV da Enfermaria do Departamento de Clínica Médica do Hospital de Clínicas da UFPR

2. Médico Especialista em Clínica Médica e Medicina de Urgência pela SBCM. Supervisor Médico da Unidade Semi-Intensiva do Hospital de Clínicas da UFPR. Vice-preceptor do Setor IV da Enfermaria do Departamento de Clínica Médica do Hospital de Clínicas da UFPR. Mestrando em Medicina Interna da UFPR.

3. Médico Residente em Reumatologia do Hospital de Clínicas da UFPR.

4. Médica Residente de Neurologia do Hospital de Clínicas da UFPR.

5. Acadêmico de Medicina do sexto ano da Universidade Federal do Rio Grande do Sul (UFRGS), Porto Alegre, RS, Brasil.
}

Endereço para correspondência: Dr. Acir Rachid. Alameda Princesa Izabel, 1.223-ap.71, CEP 80.470-150. Curitiba, PR, Brasil. E-mail: fcomagalhaes@uol.com.br 
O comprometimento pulmonar decorre da fraqueza primária dos músculos torácicos, que favorece um acúmulo de secreções e hipoventilação alveolar, e também pela doença pulmonar intersticial, que em sua forma mais severa é caracterizada por lesão alveolar difusa, usualmente associada à presença de anticorpos anti-Jo-1 ou outra t-RNA sintetase. Pode haver também sofrimento pulmonar em decorrência de múltiplos episódios de aspiração conseqüente ao refluxo esofágico.

A associação de câncer com miopatia inflamatória pode ocorrer, especialmente em grupos etários mais avançados. A incidência de carcinoma de pulmão, intestino e linfoma não-Hodgkin pode estar aumentada em pacientes com PM, especialmente no primeiro ano após o diagnóstico ${ }^{(7,8)}$.

Manifestações atípicas de doenças incomuns fazem parte do cenário de grandes hospitais-escola de nível terciário; portanto, dentro deste espírito acadêmico, relatamos caso pouco usual de comprometimento de língua na PM.

\section{RELATO DO CASO}

Paciente do sexo feminino, 54 anos de idade, com diagnóstico de hipotiroidismo há um ano em uso de levotiroxina $75 \mathrm{mcg} / \mathrm{d}$ com quadro clínico e laboratorial compensado há oito meses relatava, desde então, o aparecimento na língua de lesão com características lineares, esbranquiçadas, inicialmente pequenas e que progressivamente passaram a ocupar toda a língua e mucosa oral. Associado ao quadro, relatava glossalgia, disfagia, perda do paladar, parestesia em cavidade oral e região perioral. Houve perda ponderal de $15 \mathrm{~kg}$ nos últimos seis meses e referia persistentemente astenia desde o início do quadro que progressivamente evoluiu para sensação de fraqueza muscular nos membros.

Ao exame físico, apresentava língua com lesões ulceradas em toda sua extensão, de aspecto linear com secreção esbranquiçada nas bordas e atrofia de hemilíngua esquerda (Figura 1). Mucosa oral hiperemiada. Ausculta cardíaca e pulmonar normais. Mamas sem alterações. Abdome plano, flácido e indolor à palpação, sem alterações de vísceras ou massas palpáveis Membros inferiores com edema +/IV. Exame neurológico mostrou pares cranianos inalterados, força muscular grau IV proximal e $\mathrm{V}$ distal nos membros superiores e grau $\mathrm{V}$ proximal no membro inferior direito e IV proximal no membro inferior esquerdo e grau $\mathrm{V}$ distal bilateral nos membros inferiores. Reflexos grau III global e simétricos. Sensibilidade normal (profunda e superficial). Eutrófica e eutônica.

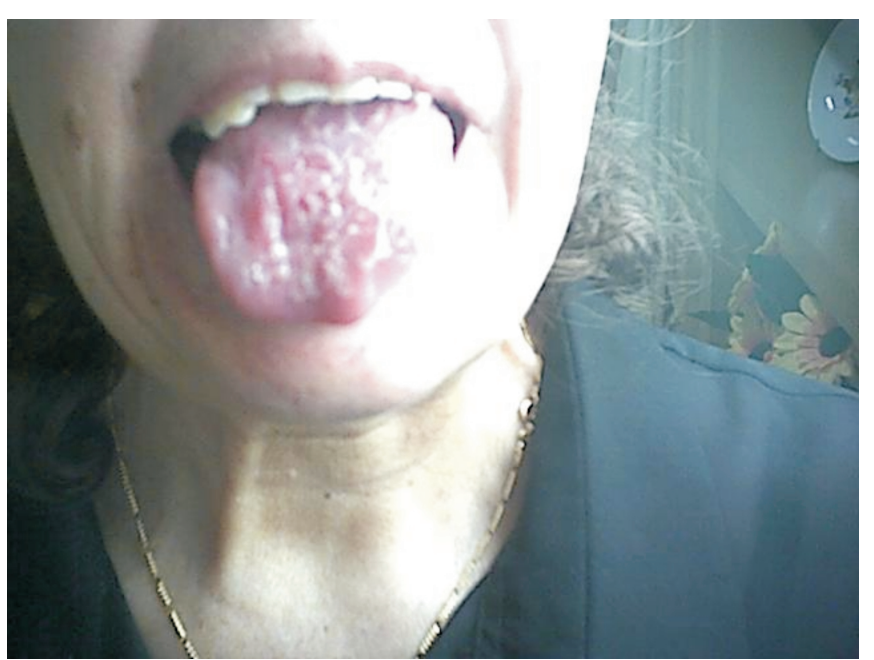

Figura 1 - Aspecto da língua com hiperemia e ulcerações lineares

Inicialmente, o hemograma e a bioquímica eram normais. Durante a evolução apresentou provas de atividade inflamatória com PCR: 0,207 (até 0,50) e VHS: 20 (1 a 20). Exames da secreção da língua para BAAR e micológico direto foram negativos. Primeira dosagem CPK: 2390 (26 a 140), fator reumatóide: 13,6 (até 20). Sorologia hepatite B e C: negativas. Antitireoglobulina: 1084 (até 40). Antiperoxidase: 61,60 (até 35). TSH: 2,270 (0,4 a 4,0). T4 Livre: 1,53 (0,8 a 1,9). Crioaglutininas: 1:32 (até 1:64). FAN: $>1: 640$ (até 1:80) com padrão nuclear pontilhado fino. Segunda dosagem CPK: 1152 (26 a 140). CA-125: 13,0U/mL (ND a 35,0).

A partir do quadro clínico e com enzima muscular elevada foi sugerido o diagnóstico de PM. Endoscopia digestiva alta evidenciou esôfago de Barrett, com úlcera esofágica e hérnia hiatal. Anatomia patológica da biópsia mostrou esofagite crônica e aguda ulcerada com metaplasia colunar juncional. Ultra-sonografia do abdome e pélvica normais. Realizou-se ressonância nuclear magnética (RNM) encefálica, a qual mostrou sulcos corticais das regiões frontais de ambos os hemisférios cerebrais proeminentes. Pequeno foco hiperintenso nas seqüências ponderadas em T2, localizado na região subcortical do lobo frontal do hemisfério cerebral direito podendo corresponder à área de microangiopatia. Ecografia do pescoço e tireóide demonstrou cisto de $4 \mathrm{~mm}$ com calcificação parietal no seu terço médio. Estruturas vasculares preservadas. Ausência de linfonodomegalia.

A eletroneuromiografia (ENMG) mostrou um padrão miopático com sinais de desinervação ativa nos músculos testados compatível com miopatia inflamatória. Realizou-se 
biópsia no bíceps braquial direito, que mostrou, por meio de HE-TRICROMO, tecido endomisial normal; ausência de infiltração por tecido adiposo; vasos com infiltrado inflamatório perivascular, sem invasão de paredes, constituído por linfomononucleares; nervos ausentes da preparação; variação moderada do diâmetro das fibras, com fibras atróficas poliédricas e raramente anguladas, dispersas entre as fibras normais; núcleos múltiplos na periferia; raras fibras com necrose e fagocitose discreta; ausência de reação inflamatória intersticial; quadro histológico muscular compatível com miopatia inflamatória e sinais sugestivos de vasculite.

Realizou-se pulsoterapia com metilprednisolona 500mg durante cinco dias, após a qual houve melhora progressiva das queixas de fraqueza proximal e desaparecimento completo da dor e lesões na língua. Continua em acompanhamento ambulatorial com corticoterapia e metotrexato.

\section{DISCUSSÃO}

A literatura não apresenta muitos trabalhos sobre sintomas incomuns na PM, o que nos levou a publicar o presente caso. Na pesquisa bibliográfica realizada encontrou-se apenas um artigo no qual o autor supõe ter sido o primeiro caso registrado na literatura médica da participação da língua na $\mathrm{PM}^{(9)}$. Encontrou-se, também, o registro de participação

\section{REFERÊNCIAS}

1. Scola RH, Werneck LC, Prevedello DMS: Polimiosite e dermatomiosite. Dendrito, Curitiba, v. 4, p. 77-82, 1999.

2. Yazici Y, Kagen L: Clinical presentation of the idiopathic inflammatory myopathies. Rheum Dis Clin North Am 28: 823-32, 2002.

3. Delakas MC: Muscle biopsy findings in inflammatory myopathies. Rheum Dis Clin North Am 28: 779-98, 2002.

4. Miller FW: Myositis-specific autoantibodies. Touchstones for understanding the inflammatory myopathies. JAMA 270: 1846-9, 1993.

5. Lundeberg LE, Dastmalchi W: Possible pathogenic mechanisms in inflammatory myopathies. Rheum Dis Clin North Am 28: 799-822, 2002.

6. Wortmann RH, Di Mauro S: Differenciating idiopathic inflammatory myopathies from metabolic myopathies. Rheum Dis Clin North Am 28: 759-78, 2002. da língua em uma doença mista do tecido conjuntivo, tendo o autor também afirmado que se tratava da primeira publicação nesse contexto ${ }^{(10)}$, e ainda o relato da participação da língua em uma miosite granulomatosa ${ }^{(11)}$.

Os achados clínicos e laboratoriais descritos para essa paciente de 54 anos de idade incluem o raro comprometimento da língua, caracterizado por lesões lineares e esbranquiçadas, inicialmente limitadas a pequenas porções da língua e que evoluíram com o comprometimento de toda a mucosa oral, acompanhado de alterações na sensibilidade e atrofia de hemilíngua. Essas manifestações antecederam o quadro de fraqueza muscular proximal, característico da PM. Com o aparecimento da fraqueza muscular proximal dos membros superiores e inferiores, associado à elevação de enzimas musculares e achados eletromiográficos e histológicos típicos de miopatia inflamatória, firmou-se o diagnóstico de PM. A pulsoterapia com corticóide trouxe uma rápida melhora do quadro clínico e laboratorial, que coincidiu com o desaparecimento das alterações na língua, reforçada pela melhora mantida e evolução clínica favorável. Assim sendo, esse relato representa a descrição do segundo caso de PM envolvendo o acometimento pouco usual da língua, e como curiosidade, o fato de a paciente ter se apresentado inicialmente apenas com queixa de dor na língua.

7. Buchbinder R, Forbes A, Hall S, Dennett X, Giles G: Incidence of malignant disease in biopsy-proven inflammatory myopathy. A population-based cohort study. Ann Intern Med 134: 1087-95, 2001.

8. Ramanan AV, Feldmann BM: Clinical features and outcomes in juvenile dermatomyositis and other childhood onset Myositis syndromes. Rheum Dis Clin North Am 28: 833-57, 2002.

9. Khan AR, Bertorini TE, Horner LH: Tongue involvement in a patient with granulomatous myositis. South Med J 90: 937-9, 1997.

10. Gibson L, Lamey PJ, Zoma A, Ballantyne J: Tongue atrophy in mixed connective tissue disease. Oral Surg Oral Med Oral Pathol Oral Radiol Endod 71: 294-6, 1991.

11. Chauvet E, Sailler L, Carreiro M, et al: Symptomatic macroglossia and tongue myositis in polymyositis: treatment with corticosteroids and intravenous immunoglobulin. Arthritis Rheum 46: 2762-4, 2002. 